and guinea-pig airways. Am J Respir Cell Mol Biol 1998; 18: 279-285.

9 Said SI, Rattan S. The multiple mediators of neurogenic smooth muscle relaxation. Trends Endocrinol Metab 2004; 15 : 189-191.

10 Szema AM, Hamidi SA, Lyubsky S, et al. Mice lacking the VIP gene show airway hyperresponsiveness and airway inflammation, partially reversible by VIP. Am J Physiol Lung Cell Mol Physiol 2006; 291: L880-L886.

11 Hamidi SA, Prabhakar S, Said SI. Enhancement of pulmonary vascular remodelling and inflammatory genes with VIP gene deletion. Eur Respir J 2008; 31: 135-139.

DOI: $10.1183 / 09031936.00131008$

\title{
Are asymptomatic airway hyperresponsiveness and allergy risk factors for asthma? A longitudinal study
}

\section{To the Editors:}

We read with interest the recent paper by VAN DEN NIEUWENHOF et al. [1] who reported no statistically significant association of airway hyperresponsiveness (AHR) with asthma incidence over 14 yrs in 123 asymptomatic adolescents aged 10-22 yrs at baseline. They concluded that AHR is not a risk factor for the development of asthma in adulthood and that screening for AHR in adolescents to detect subjects at risk for asthma cannot be recommended. We similarly assessed the association between AHR at baseline and asthma incidence over 11.4 yrs among 172 asymptomatic children (44.2\% with AHR (provocative dose causing a $20 \%$ fall in forced expiratory volume in one second $<4 \mathrm{mg}$ methacholine) at baseline) and 517 adults (31.7\% with AHR at baseline) from the Epidemiological Study on the Genetics and Environment of Asthma (EGEA) [2, 3]. Asymptomatic adults were defined as those with a null symptomatic score according to PEKKANEN et al. [4] over the previous 12 months. The score is based on asthma-like symptoms (wheeze with breathlessness, woken with chest tightness, attack of shortness of breath (SOB) at rest, attack of SOB after exercise, woken by attack of SOB) and is already used in the EGEA study [5] and, with a similar definition, in children. Asthma incidence was $14.0 \%$ in children and $8.3 \%$ in adults. Asymptomatic AHR appeared to be significantly related to asthma incidence both in children and adults. The association remained statistically significant after adjustment for age, sex and atopy at baseline (positive skin prick test to any of 11 allergens) and taking into account familial dependence in children (odds ratio (OR) 3.39, 95\% confidence interval (CI) 1.09-10.53, $\mathrm{n}=145$ ) and in adults (OR $2.68,95 \%$ CI $1.08-6.69, \mathrm{n}=377)$. The results were similar when considering subjects in the same age range (10-22 yrs) as those of VAN DEN NIEUWENHOF et al. [1] (OR 3.16, 95\% CI 1.23-8.14, $\mathrm{n}=158$ ) and remained after exclusion of atopics (OR 5.84, 95\% CI 1.06-32.10, $\mathrm{n}=89$ ). The conclusions were similar (ORs always $>2$ ) when considering other definitions of asymptomatic subjects. When including any wheeze and chronic cough in the preceding list of symptoms, as VAN DEN NIEUWENHOF et al. [1] did, AHR at baseline remained significantly associated with asthma incidence among children (OR 3.18, 95\% CI 1.08-9.37, n=142), adults (OR $2.84,95 \%$ CI 1.08-7.42, $\mathrm{n}=343$ ), or those aged 10-22 yrs (OR 3.27, 95\% CI 1.11-9.69, n=149). Furthermore, when asymptomatic adult subjects where defined by the absence of chronic cough, chronic phlegm, dyspnoea or wheezing, as per BRUTSCHE et al. [6] in the SAPALDIA study, AHR was also associated with asthma incidence (OR 2.40, 95\% CI 1.06-5.49, n=387).

Methacholine AHR was significantly related to asthma incidence in asymptomatic subjects from the EGEA study, whatever the association of symptoms used to define asymptomatic subjects in the previous 12 months and age range at baseline. Results were similar after adjusting for age, sex and atopy or restricting the analysis to those aged 10-22 yrs as in the study by VAN DEN NIEUWENHOF et al. [1], and even when restricting the analysis to nonatopic subjects in that age range. Although no significant association of AHR with asthma incidence was shown in the study of VAN DEN NIEUWENHOF et al. [1], it is interesting to note that the OR observed was $>2$ (2.20), an association of similar magnitude to the association observed in the EGEA study. The differences are likely to depend on the greater statistical power of the EGEA study, but could also relate to the design of the study, which includes families of asthmatics [2]. Besides being of prognostic significance for asthma persistence [7], AHR appears to be predictive of asthma incidence among asymptomatic subjects. However, such statistical association is insufficient to conclude that screening for asthma among asymptomatic adolescents is worthwhile, an aspect which needs specific evaluation. The main interest lies in the understanding of various aspects of asthma expression. Specific determinants (hormonal, personal, occupational and general environmental) may explain the heterogeneity of asthma expression over the lifespan.

Large representative samples with repeated measurements are needed to clarify the temporality of symptoms, hyperresponsiveness and asthma diagnosis, as the expression of both symptoms and airway hyperresponsiveness are variable, in particular in the sensitive period of adolescence [7, 8]. 
The Epidemiological Study on the Genetics and Environment of Asthma (EGEA) Cooperative group comprises the following. Coordination: F. Kauffmann (INSERM U780, Villejuif, France); F. Demenais (genetics; INSERM U794, Paris, France); I. Pin (clinical aspects; INSERM U823, La Tronche, France). Respiratory epidemiology: M. Korobaeff, F. Neukirch (EGEA1, INSERM U700, Paris); I. Annesi-Maesano (INSERM U707, Paris); F. Kauffmann, N. Le Moual, R. Nadif, M.P. Oryszczyn (INSERM U780); V. Siroux INSERM U823, Grenoble, France). Genetics: J. Feingold (INSERM U393, Paris); M.H. Dizier (INSERM U535, Villejuif); E. Bouzigon, F. Demenais (INSERM U794, Paris); I. Gut, M. Lathrop (Centre National de Génotypage, Evry, France). Clinical centres: I. Pin, C. Pison (Grenoble); D Ecochard (EGEA1), F Gormand, Y Pacheco (Lyon, France); D Charpin (EGEA1), D Vervloet (Marseille, France); J Bousquet (Montpellier, France); A. Lockhart (EGEA1, Cochin, Paris); R. Matran (Cochin, Paris); E. Paty, P. Scheinmann (Paris Necker, France); A. Grimfeld, J. Just (Paris-Trousseau, France). Data and quality management: J. Hochez (INSERM ex-U155 (EGEA1)); N. Le Moual, C. Ravault (INSERM U780); N Chateigner (INSERM U794); J. Ferran (Grenoble).

\section{E. Rage*, V. Siroux", N. Le Moual*, I. Pin" and F. Kauffmann* *INSERM U780 and Université Paris-Sud, Villejuif, and "INSERM U823, Grenoble, France.}

\section{SUPPORT STATEMENT}

Supported by Agence Nationale de la Recherche (ANR)-SantéEnvironnement et Santé-Travail, ANR-Collection d'Échantillons Biologiques de la Santé, Agence Française de Sécurité Sanitaire de l'Environnement et du Travail and Programme Hospitalier de Recherche Clinique Paris (all Paris, France).

\section{STATEMENT OF INTEREST}

None declared.

\section{REFERENCES}

1 van den Nieuwenhof L, Schermer T, Heijdra Y, et al. Are asymptomatic airway hyperresponsiveness and allergy risk factors for asthma? A longitudinal study. Eur Respir J 2008; 32: 70-76.

2 Kauffmann F, Dizier MH, Pin I, et al. Epidemiological study of the genetics and environment of asthma, bronchial hyperresponsiveness, and atopy: phenotype issues. Am J Respir Crit Care Med 1997; 156: S123-S129.

3 Pin I, Siroux V, Ferran J, et al. 12-year follow-up of the Epidemiological study for the Genetics and Environment of Asthma (EGEA) - Asthma incidence: preliminary results. Eur Respir J 2006; 28: Suppl. 50, 238s.

4 Pekkanen J, Sunyer J, Anto JM, Burney P. Operational definitions of asthma in studies on its aetiology. Eur Respir $J$ 2005; 26: 28-35.

5 Rage E, Siroux V, Künzli N, Pin I, Kauffmann F. Air pollution and asthma severity in adults. Occup Environ Med 2008; [Epub ahead of print PMID: 19017701].

6 Brutsche $\mathrm{MH}$, Downs $\mathrm{SH}$, Schindler $\mathrm{C}$, et al. Bronchial hyperresponsiveness and the development of asthma and COPD in asymptomatic individuals: SAPALDIA cohort study. Thorax 2006; 61: 671-677.

7 Sears MR, Greene JM, Willan AR, et al. A longitudinal, population-based, cohort study of childhood asthma followed to adulthood. N Engl J Med 2003; 349: 1414-1422.

8 Gerritsen J. Airway responsiveness in teenagers is becoming sexier. Am J Respir Crit Care Med 2008; 178: 321-324.

DOI: $10.1183 / 09031936.00135108$

\section{Anti-elastin autoantibodies are not present in combined pulmonary fibrosis and emphysema}

\section{To the Editors:}

Whereas tobacco smoking is a well-established risk factor for the development and progression of chronic obstructive pulmonary disease (COPD), the molecular basis for individual predisposition and disease progression remains largely unknown. Immunological processes and especially autoreactive immune processes have recently been implicated, with anti-elastin antibodies and a T-helper type-1 lymphocyte response identified in patients with COPD/emphysema [1]. Immune mechanisms are also implicated in interstitial lung disease and pulmonary fibrosis [2], and smoking-induced autoimmunity has been demonstrated in rheumatoid arthritis [3].
We explored whether an autoimmune process implicating anti-elastin autoantibodies and facilitated by tobacco smoking may take place in patients with combined pulmonary fibrosis and emphysema (CPFE), a distinct entity recently defined on the basis of characteristic features of chest imaging, pulmonary function and outcome [4]

Patients with CPFE, diagnosed within the previous 5 yrs using published criteria based on computed tomography of the chest [4], were studied. Patients with connective tissue disease at the time of diagnosis were excluded. Control patients were selected from within the same department of respiratory medicine and had various diagnoses: idiopathic 